\title{
Efficient Sonogashira and Suzuki-Miyaura coupling reaction catalyzed by Pd-Nanoparticles
}

\author{
KISHOR E BALSANE, SURESH S SHENDAGE and JAYASHREE M NAGARKAR* \\ Department of Chemistry, Institute of Chemical Technology, Matunga, Mumbai 400019, India \\ e-mail: jm.nagarkar@ictmumbai.edu.in; jayashreenagarkar@yahoo.co.in
}

MS received 13 May 2014; revised 15 July 2014; accepted 27 July 2014

\begin{abstract}
The Pd nano particles were electrochemically deposited on nafion-graphene. They showed excellent catalytic activity towards Sonogashira and Suzuki-Miyaura cross-coupling reaction. Benzenediazonium salts were used as alternative to aromatic halide. The developed protocol offers recyclability, easy workups with short reaction time and good-to-excellent product yield.
\end{abstract}

Keywords. Electrochemistry; Palladium nanoparticles; Nafion-graphene; heterogeneous recyclable catalyst.

\section{Introduction}

Various cross-coupling reactions such as Suzuki, Heck and Sonogashira have been used in organic synthesis. ${ }^{1}$ These reactions have wide industrial applications in synthesizing pharmaceutical and agrochemical compounds. ${ }^{2}$ Recently, Sonogashira and Suzuki crosscoupling reactions were extensively studied for the C-C bond forming transformations. A number of homogeneous palladium catalysts such as $\mathrm{Pd}(\mathrm{II})$ phosphineylide complexes, ${ }^{3} \mathrm{Pd}(\mathrm{II})$ diamino carbine, ${ }^{4}$ oxime-based palladacycle ${ }^{5}$ and $\mathrm{Pd}(\mathrm{OAc})_{2}, \mathrm{Pd}_{2} \mathrm{dba}_{3}$ with appropriate ligands, ${ }^{6}$ have been reported to achieve these transformations with the advantages of fast reaction rates, good selectivity and high product yield. ${ }^{7}$ However, these homogeneous catalytic systems have some limitations. The ligands used in the above reported methods are either very expensive or their synthesis is very tedious. Moreover, the catalysts are not reusable. Heterogeneous catalysts can be recovered and reused at least for a few cycles as compared to homogeneous catalytic systems. A number of heterogeneous catalysts such as Pd on MOF- $5,{ }^{8}$ hybrid silica based Pd(II)complex, ${ }^{9}$ organosilica-SBA-15, ${ }^{10}$ Pd-grafted mesoporus silica, ${ }^{11}$ and $\mathrm{Pd}(0) / \mathrm{BaSO}_{4},{ }^{12}$ were reported. Polymer-supported $\mathrm{N}$-heterocyclic carbene-palladium, ${ }^{13}$ palladium on charcoal $^{14}$ and aluminum hydroxide-supported palladium nanoparticles ${ }^{15}$ have also been reported as catalysts. It is observed that the supporting material plays an important role in catalytic activity of heterogeneous catalyst. In most of the cases, the supported heterogeneous Pd catalyst suffers from problems such as

\footnotetext{
*For correspondence
}

thermal instability, high surface area and agglomeration of nanoparticles. Graphene has wide scope in catalysis as a support material due to its high surface area, thermal as well as mechanical stability, and electrical conductivity. ${ }^{16,17}$ Additionally, graphene has applications in various fields such as fuel cell, nanocomposite materials and electronic devices. ${ }^{18-20}$ The electrochemically synthesized catalyst is environmentally favourable having high stability and large surface area with dispersed Pd nanoparticles. Besides these advantages, electrochemical processes are heterogeneous in nature which regulates the size and morphology of $\mathrm{Pd}$ nano particles. Various coupling reactions were carried out by using electrochemically synthesized nano-Pd catalysts. ${ }^{21,22}$ Earlier, we have reported electrochemically synthesized nano-Pd particles on nafion-graphene support (Pd/Nf-G) as an efficient heterogeneous catalyst for Suzuki coupling reaction. ${ }^{23}$ Herein we report the Sonogashira and Suzuki-miyaura coupling reactions by using electrochemically synthesized Pd on nafion-graphene support as a catalyst. The Sonogashira cross coupling between aryl halides and terminal alkynes is one of the important reactions in organic chemistry. We have carried out the ligandfree, copper co-catalyst-free and amine-free synthesis of aryl alkynes from substituted iodobenzenes and bromobenzenes with phenyl acetylene derivatives in ethanol as the solvent and $\mathrm{K}_{2} \mathrm{CO}_{3}$ as the base at $78^{\circ} \mathrm{C}$. The reaction time varies from $6-12 \mathrm{~h}$ depending on the nature of substituted aryl halide (scheme 1).

The research work was further extended to explore the catalytic activity of Pd/Nf-G for SuzukiMiyuara cross coupling reactions. Benzenediazonium tetrafluroborate salts are the best alternative to the very 


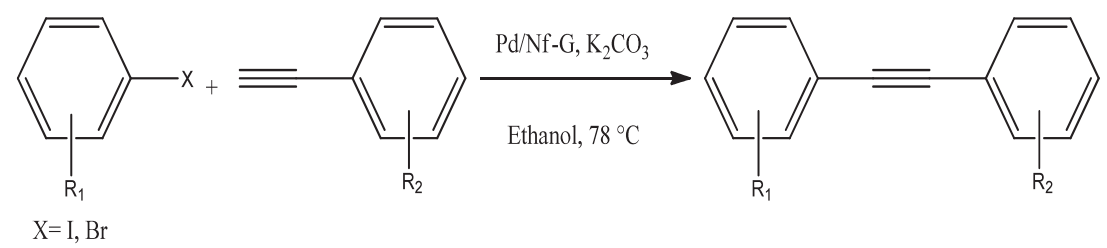

Scheme 1. Sonogashira coupling reaction catalyzed by Pd/Nf-G.



Scheme 2. Suzuki-Miyaura scoupling reaction catalyzed by Pd/Nf-G.

Table 1. Optimization of reaction parameters for Sonogashira reaction catalyzed by Pd/Nf-G. ${ }^{a}$

\begin{tabular}{lllllll}
\hline Entry & Solvent & Base & Temp ${ }^{\circ} \mathrm{C}$ & Catalyst loading (mol\%) & Time $(\mathrm{h})$ & Yield $^{\mathrm{b}}(\%)$ \\
\hline 1. & $\mathrm{CH}{ }_{3} \mathrm{CN}$ & $\mathrm{K}_{2} \mathrm{CO}_{3}$ & 80 & 0.3 & 9 & 45 \\
2. & DMF & $\mathrm{K}_{2} \mathrm{CO}_{3}$ & 100 & 0.3 & 8 & 65 \\
3. & Water & $\mathrm{K}_{2} \mathrm{CO}_{3}$ & 100 & 0.3 & 10 & 50 \\
4. & Ethanol-Water (1:1) & $\mathrm{K}_{2} \mathrm{CO}_{3}$ & 78 & 0.3 & 9 & 66 \\
5. & Dioxane & $\mathrm{K}_{2} \mathrm{CO}_{3}$ & 100 & 0.3 & 6 & 70 \\
6. & Ethanol & Pyrolidine & 78 & 0.3 & 6 & 58 \\
7. & Ethanol & $\mathrm{TEA}$ & 78 & 0.3 & 6 & 95 \\
8. & Ethanol & $\mathrm{K}_{2} \mathrm{CO}_{3}$ & 78 & 0.3 & 6 & 92 \\
9. & Ethanol & $\mathrm{K}_{2} \mathrm{CO}_{3}$ & 78 & 0.2 & 8 & 88 \\
10. & Ethanol & $\mathrm{K}_{2} \mathrm{CO}_{3}$ & 78 & 0.1 & 6 & 97 \\
11. & Ethanol & $\mathrm{K}_{2} \mathrm{CO}_{3}$ & 78 & 0.4 & 67 \\
\hline
\end{tabular}

${ }^{a}$ Reaction conditions: iodobenzene $(0.5 \mathrm{mmol})$, phenyl acetylene $(0.75 \mathrm{mmol})$, base $(1.25 \mathrm{mmol})$, solvent $(3 \mathrm{~mL})$, catalyst $\mathrm{Pd} / \mathrm{Nf}-\mathrm{G}(0.3 \mathrm{~mol} \%)$, temperature $\left(78^{\circ} \mathrm{C}\right)$.

${ }^{\mathrm{b}}$ Isolated yield based on column chromatography.

expensive aryl halides. Hence, the Suzuki-Miyaura cross-coupling reactions were carried out by using substituted boronic acids and various benzenediazonium tetrafluroborate salts in methanol as solvent. The reactions were carried out at ambient temperature with reaction time varying from $2-4 \mathrm{~h}$ (scheme 2 ).

\section{Experimental}

\subsection{Chemicals}

All chemicals are of analytical grade and are used without further purification. Graphite powder, sulphuric acid, sodium nitrate, hydrogen peroxide $(30 \mathrm{wt} \%)$, ammonia solution, hydrochloric acid, hydrazine hydrate, ethanol were procured from Merck. $5 \mathrm{wt} \%$ Nafion solution in lower aliphatic alcohols (Alfa
Aesar), palladium (II) chloride (99.9\%) were purchased from Sigma-Aldrich.

\subsection{Preparation of graphene oxide}

The graphene oxide (GO) was prepared from graphite by using Hummers method. ${ }^{24}$ Initially $1 \mathrm{gm}$ of graphite powder was added to previously cooled $50 \mathrm{~mL}$ concentrated $\mathrm{H}_{2} \mathrm{SO}_{4}$ in round bottom flask, followed by addition of $0.8 \mathrm{~g}$ of $\mathrm{NaNO}_{3}$. Then $3 \mathrm{~g}$ of $\mathrm{KMnO}_{4}$ was added slowly and by maintaining the temperature of reaction mass below $20^{\circ} \mathrm{C}$. The reaction mixture was stirred for $30 \mathrm{~min}$ at $35^{\circ} \mathrm{C}$ followed by addition of $46 \mathrm{~mL}$ distilled water with continuous stirring. The resulting suspension was heated at $97^{\circ} \mathrm{C}$ for $15 \mathrm{~min}$. The suspension was cooled to room temperature and then $10 \mathrm{~mL}$ of $30 \%$ $\mathrm{H}_{2} \mathrm{O}_{2}$ was slowly added to it with constant stirring. The entire suspension was centrifuged to get GO. It was 
washed with $5 \% \mathrm{HCl}$ followed by distilled water and finally with ethanol. The obtained GO was dried under vacuum for $12 \mathrm{~h}$ at $60^{\circ} \mathrm{C}$.

\subsection{Synthesis of graphene}

The GO powder was dispersed in distilled water $(0.05 \mathrm{wt} \%)$ and subjected to ultrasonication for $10 \mathrm{~min} .25 \mathrm{~mL}$ of dispersion was transferred to $100 \mathrm{~mL}$ round bottom flask followed by addition of $44 \mathrm{~mL}$ of distilled water, $154 \mu \mathrm{L}$ of ammonia and $22 \mu \mathrm{L}$ of hydrazine hydrate. The reaction mass was refluxed at $95^{\circ} \mathrm{C}$ for $1 \mathrm{~h}$ to get a homogeneous dispersion of graphene.

\subsection{Preparation of $N f-G$ platinum plate}

From above solution, $50 \mu \mathrm{L}$ graphene dispersion having concentration $(0.18 \mu \mathrm{g} / \mu \mathrm{L})$ was added to the $100 \mu \mathrm{L}$ of $5 \mathrm{wt} \%$ Nafion-ethanol solution and the mixture was sonicated for $100 \mathrm{~s}$ to get the homogeneous dispersion. $\mathrm{Nf}-\mathrm{G}$ dispersion was spread over the platinum plate by using syringe and the plate was subsequently dried in air to get thin film of Nf-G.

Table 2. $\mathrm{Pd} / \mathrm{Nf}-\mathrm{G}$ catalyzed Sonogashira reaction of various aryl iodide and bromide with various phenyl acetylene. ${ }^{\mathrm{a}}$

\begin{tabular}{|c|c|c|c|c|c|}
\hline Entry & Aryl halides & Phenyl Acetylene & Products & Time (h) & Yield $^{\mathrm{b}}(\%)$ \\
\hline 1. & & & & 6 & 97 \\
\hline 2. & & & & 6 & 97 \\
\hline 3. & & & & 7.5 & 95 \\
\hline 4. & & & & 6 & 96 \\
\hline 5. & $\mathrm{H}_{3} \mathrm{CC}$ & & & 7 & 94 \\
\hline 6. & $\mathrm{H}_{3} \mathrm{Cl}$ & & & 8 & 94 \\
\hline 7. & & & & 9 & 93 \\
\hline 8. & & & & 10 & 91 \\
\hline 9. & & & & 10 & 89 \\
\hline 10. & & & & 10 & 89 \\
\hline 11. & & & & 8 & 93 \\
\hline 12. & & & & 10 & 94 \\
\hline 13. & & & & 11 & 92 \\
\hline 14. & & & & 12 & 65 \\
\hline 15. & & & & 12 & 58 \\
\hline 16. & & & & 10 & 75 \\
\hline 18. & & & & 6 & 97 \\
\hline 19. & & & & 8 & 90 \\
\hline
\end{tabular}

${ }^{a}$ Reaction conditions: aryl halide $(0.5 \mathrm{mmol})$, phenyl acetylene $(0.75 \mathrm{mmol}), \mathrm{K}_{2} \mathrm{CO}_{3}(1.25 \mathrm{mmol})$, ethanol $(3 \mathrm{~mL})$, catalyst $\mathrm{Pd} / \mathrm{Nf}-\mathrm{G}(0.3 \mathrm{~mol} \%)$, temperature $78^{\circ} \mathrm{C}$.

${ }^{\mathrm{b}}$ Isolated yield based on column chromatography. 


\subsection{Electrochemical deposition of Pd NPs on $N f-G$ modified Pt plate}

The electrochemical deposition of $\mathrm{Pd}$ was carried out in aqueous solution of $10 \mathrm{mM} \mathrm{PdCl}_{2}$ at $-0.2 \mathrm{~V}$ for the period of $60 \mathrm{~s}$ by using three electrode cyclic voltammetry technique. In this system, the Nf-G modified Pt plate as the working electrode, saturated calomel (SCE) as the reference and platinum rod as the counter electrode were used. Pt plate was removed from solution after $60 \mathrm{~s}$ and dried in the air. The deposited Pd NPs on to Nf-G film were scrapped with stainless steel blade and preserved for further use.

\section{Result and Discussion}

\subsection{Sonogashira reaction}

Our first approach was to optimize reaction conditions for the reaction between iodobenzene and phenylacetylene as a model reaction. The results are summarized in table 1 . We started optimization study with variety of solvents (table 1, entry 1-6). All the solvents gave good conversion but the excellent results were obtained with ethanol. Ethanol also helped in reducing the leaching of Pd nano particles (table 1, entry 8). Ethanol-water or water as solvent gave lower product yield (table 1, entries 3-4). Sonogashira coupling is strongly influenced by the nature of the base. We have applied several bases (table 1, entries 6-8) among which $\mathrm{K}_{2} \mathrm{CO}_{3}$ gave maximum conversion and selectivity (table 1 , entry 8). Increase in Pd content from $0.3 \mathrm{~mol} \%$ to $0.4 \mathrm{~mol} \%$ did not show any significant increase in product yield (table 1, entries 8 and 11). Therefore, $0.3 \mathrm{~mol} \% \mathrm{Pd}$ loading at $78^{\circ} \mathrm{C}$ temperature and $6 \mathrm{~h}$ reaction time were the optimized reaction parameters for the model reaction (table 1, entry 8).

Under these optimized conditions, we carried out substrate study using various substituted iodo and bromo benzene derivatives and phenyl acetylene as starting materials. We tried reaction of both electron donating as well as electron withdrawing substituents of iodobenzene and bromobenzene with substituted phenyl acetylene which exhibits excellent reactivity towards the Pd/Nf-G. The electron withdrawing substituents (table 2 entries $2-5,16$ ) gave greater yield as compared to electron donating groups (table 2 entries 6-10, 12-13). The electron withdrawing groups facilitate the removal of iodide and bromo group. Some heterocyclic iodo derivatives also gave excellent yields (table 2 entries 12-13). The 2-hydroxy iodobenzene gave lower yield as compared to that of 4-hydroxy iodobenzene which may be due to steric hindrance (table 2, entries 8-9). Excellent product yields were obtained when we carried out experiments using substituted phenyl acetylene. It was found that the catalyst showed good activity for electron donating group as compared to electron withdrawing group (table 2, entries 18-19).

\subsection{Suzuki-Miyaura coupling reaction}

We further explored the applicability of catalyst $\mathrm{Pd} /$ Nf-G for the Suzuki-Miyaura reaction between

Table 3. Optimization of reaction parameters for Suzuki-Miyaura reaction between benzenediazonium tetrafluroborate salt with boronic acid catalyzed by Pd/Nf-G. ${ }^{a}$

\begin{tabular}{|c|c|c|c|c|c|}
\hline Entry & Solvent & Temp. $\left({ }^{\circ} \mathrm{C}\right)$ & Pd Loading (mol\%) & Time (h) & Yield $^{\mathrm{b}}(\%)$ \\
\hline 1. & Water & 25 & 0.2 & 3 & 75 \\
\hline 2. & Ethanol & 25 & 0.2 & 4 & 85 \\
\hline 3. & Dioxane & 25 & 0.2 & 9 & Traces \\
\hline 4. & DCM & 25 & 0.2 & 12 & Traces \\
\hline 5. & DMSO & 25 & 0.2 & 4 & 80 \\
\hline 6. & DMF & 25 & 0.2 & 4 & 65 \\
\hline 7. & i-PrOH & 25 & 0.2 & 4 & 89 \\
\hline 8. & DME- $\mathrm{H}_{2} \mathrm{O}(1: 1)$ & 25 & 0.2 & 4 & 50 \\
\hline 9. & THF & 25 & 0.2 & 2 & 67 \\
\hline 10. & $\mathrm{MeOH}$ & 25 & 0.2 & 2 & 95 \\
\hline 11. & $\mathrm{MeOH}$ & 25 & 0.1 & 3 & 91 \\
\hline 12. & $\mathrm{MeOH}$ & 25 & 0.3 & 2 & 95 \\
\hline 13. & $\mathrm{MeOH}$ & 40 & 0.2 & 1.5 & 58 \\
\hline 14. & $\mathrm{MeOH}$ & 15 & 0.2 & 5 & 77 \\
\hline
\end{tabular}

${ }^{a}$ Reaction conditions: Benzenediazonium tetrafluoroborate salt $(0.3 \mathrm{mmol})$, phenyl boronic acid $(0.36 \mathrm{mmol})$, solvent $(2 \mathrm{~mL})$, Catalyst Pd/Nf-G (0.2 mmol).

${ }^{\mathrm{b}}$ Isolated yield based on column chromatography. 
Table 4. $\mathrm{Pd} / \mathrm{Nf}-\mathrm{G}$ catalyzed Suzuki reactions of substituted arenediazonium salt with various boronic acids. ${ }^{\mathrm{a}}$



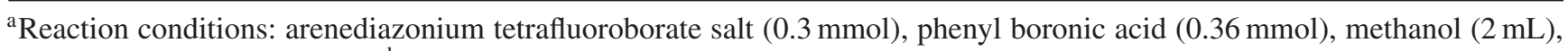
Catalyst Pd/Nf-G (0.2 mmol). ${ }^{b}$ Isolated yield based on column chromatography. 
Table 5. Recyclability study of catalyst for Sonogashira coupling reaction and Suzuki coupling reaction. ${ }^{\mathrm{a}}$

\begin{tabular}{lllllr}
\hline Run & & $1^{\text {st }}$ & $2^{\text {nd }}$ & $3^{\text {rd }}$ & $4^{\text {th }}$ \\
\hline Yield $(\%)^{\text {b }}$ & Scheme 1 & 97 & 97 & 96 & 95 \\
& Scheme 2 & 95 & 95 & 94 & 93 \\
\hline
\end{tabular}

${ }^{a}$ Reaction condition: iodobenzene $(0.5 \mathrm{mmol})$, phenyl acetylene $(0.75 \mathrm{mmol}), \mathrm{K}_{2} \mathrm{CO}_{3}(1.25 \mathrm{mmol})$, ethanol (3 mL), catalyst $\mathrm{Pd} / \mathrm{Nf}-\mathrm{G}(0.3 \mathrm{~mol} \%)$, temperature $78^{\circ} \mathrm{C}$.

${ }^{\mathrm{b}}$ Isolated yield based on column chromatography.

${ }^{a}$ Reaction condition: benzenediazonium tetrafluoroborate salt $(0.3 \mathrm{mmol})$, phenyl boronic acid $(0.36 \mathrm{mmol}), \mathrm{Methanol}(2 \mathrm{~mL})$, Catalyst Pd/Nf-G (0.2 mmol).

${ }^{\mathrm{b}}$ Isolated yield yield based on column chromatography (scheme 2).

benzenediazonium tetrafluroborate salts with phenyl boronic acid in methanol as a solvent at $25^{\circ} \mathrm{C}$ (scheme 2). This was treated as a model reaction for optimization of various parameters and the results are summarized in table 3. Methanol was found to be the most suitable solvent for the reaction and it gave higher conversion as well as yield of desired product (table 3, entries 10). When the reaction temperature was increased to $40^{\circ} \mathrm{C}$, the reactants were completely consumed within short time with the formation of impurities which consequently decreased the yield drastically (table 3, entry 13). The reaction was also carried out at $15^{\circ} \mathrm{C}$, and no significant increase in the product yield was observed even after longer reaction time. Hence the appropriate temperature for model reaction was $25^{\circ} \mathrm{C}$. Catalyst loading was also optimized and it was found that $0.2 \mathrm{~mol} \%$ of $\mathrm{Pd} / \mathrm{Nf}-\mathrm{G}$ catalyst gave higher yield of product (table 3, entries 10) as compared to $0.3 \%$ and $0.1 \mathrm{~mol} \%$ (table 3 , entries 11-12).

We further examined catalytic activity of Pd/Nf$G$ for variety of arenediazonium tetrafluroborate salts with various boronic acids which gave biaryl products in good yields. We screened phenyl boronic acid and chloro substituted phenyl boronic acid with variety of arenediazonium tetrafluroborate salts having electron donating as well as electron withdrawing substituents. The product obtained from the coupling reactions of phenyl boronic acid with arenediazonium tetrafluroborate salts gave better yield (table 4, entries 1-5) as compared to chloro-substituted boronic acid (table 4, entries 6-11). The nature of the substituted arenediazonium tetrafluroborate salt also has greater effect on the yield of product. The substituent having electron withdrawing nature was more reactive (table 4 , entries 4,5 , $9,10)$ than electron donating ones giving higher yields (table 4 , entries $2,3,7,8$ ). We also carried out reaction using 4-methoxy boronic acid and obtained good yield (table 4, entries 12-13). This study clears that the catalyst Pd/Nf-G can be applied efficiently for these coupling reactions.

\subsection{Recyclability of Pd/Nf-G for Sonogashira} (scheme 1) and Suzuki-Miyuara (scheme 2) coupling reactions

Recyclability of catalyst has greater importance for industrial applications. We also examined the recyclability of catalyst for scheme 1 and scheme 2 up to fifth cycle and catalyst showed excellent efficiency for these coupling reactions (table 5). After completion of reaction, catalyst was separated by simple filtration and was washed with ethyl acetate followed by drying at $60^{\circ} \mathrm{C}$ for $1 \mathrm{~h}$. The recovered catalyst was again reused for next run with fresh starting compounds under the similar reaction conditions. This procedure was repeated for next four batches. It was found that catalyst showed excellent activity up to fifth cycle. The palladium leaching was also investigated after $5^{\text {th }}$ run by ICP-AES which demonstrated $1.1 \mathrm{wt} \%$ and $0.9 \mathrm{wt} \%$ leaching of $\mathrm{Pd}$ for scheme 1 and scheme 2 respectively. This was also confirmed by hot filtration test for scheme 1 .

\subsection{Hot filtration test}

This test was carried out for scheme 1 (table 1, entry 1). Reaction mass was filtered after $3 \mathrm{~h}$ under hot condition and the filtrate was subjected to GC analysis which gave $58 \%$ conversion. The resultant filtrate was heated again at $78^{\circ} \mathrm{C}$ for $3 \mathrm{~h}$ and then subjected to GC analysis. The GC results did not show any increase in the product conversion. This confirms that there was no significant amount of Pd leaching during the reaction.

\section{Conclusion}

In conclusion, we report the heterogeneous, $\mathrm{Pd} / \mathrm{Nf}$ $\mathrm{G}$ catalyst which can be efficiently applied for Sonogashira and Suzuki-Miyaura coupling reactions. The catalyst was easily recoverable and reused without loss in the activity up to $5^{\text {th }}$ cycle. 


\section{Supplementary Information}

Experimental details, characterization techniques, TEM, NMR spectra, mass spectra are given as supplementary information and are available at www.ias.ac. in/chemsci.

\section{Acknowledgment}

The authors are thankful to UGC-SAP, India for the award of fellowship.

\section{References}

1. (a) Diederich F and Stang P (Eds.) 1998 In Metal-Catalyzed Cross-Coupling Reactions (New York: Wiley-VCH); (b) de Meijere A and Diederich F (Eds.) 2004 In Metal-Catalyzed Cross-Coupling Reactions $2^{\text {nd }}$ edition (Weinheim: Wiley-VCH); (c) Beller $\mathrm{M}$ and Bolm C (Eds.) 2004 In Metals for Organic Synthesis $2^{\text {nd }}$ edition (Weinheim: Wiley-VCH); (d) Johnson J B and Rovis T 2008 Angew. Chem. 47840

2. (a) Chinchilla R and Nájera C 2007 Chem. Rev. 107 874; (b) Negishi E and Anastasia L 2003 Chem. Rev. 103 1979; (c) Paterson I, Davies R D M and Marquez R 2001 Angew. Chem. 40 603; (d) Toyota M, Komori C and Ihara M 2000 J. Org. Chem. 65 7110; (e) Hassan J, Sovignon M, Gozzi E Shulz and Lemaire M 2002 Chem. Rev. 102 1359; (f) Bolm C, Hildebrand J P, Muciz K and Hermanns N 2001 Angew. Chem. 1133382

3. Lee K H, Han S W, Kwon K and Park J B 2013 J. Colloid Interface Sci. $\mathbf{4 0 3} 127$

4. Chen Xu, Xin-Hua Lou, Zhi-Qiang Wang and Wei-Jun Fu 2012 Transition Met. Chem. 37519

5. Susanto W, Chu Chi-Yuan, Ang W J, Chou Tzyy-Chao, Lo Lee-Chiang and Lam Yulin 2012 Green Chem. 1477

6. (a) Littke A F, Dai C and Fu G C $2000 \mathrm{~J}$. Am. Chem. Soc. 122 4020; (b) Barder T E, Walker S D, Martinelli J R and Buchwald S L 2005 J. Am. Chem. Soc. 127 4685; (c) Marion N, Navaroo O, Mei J, Stevens E D, Scott N M and Nolan S P 2006 J. Am. Chem. Soc. 1284101

7. (a) Yi C Y and Hua R M 2006 Cat. Comm. 7 377; (b) Sachtler W M H, Cavalcanti F A P and Zhang Z 1999 Catal. Lett. 9261

8. Gao S, Zhao N, Shu M and Che S 2010 Appl. Catal., A 388196

9. Guadalupe $\mathrm{B}$, Amàlia M, Roser $\mathrm{P}$, Teodor $\mathrm{P}$, Xavier C and Michel Wong C 2012 Eur. J. Org. Chem. 193625

10. Shaabani A and Mahyari M 2013 J. Mater. Chem. 1 9303

11. Modak A, Mondal J and Bhaumik S 2012 Green Chem. 142840

12. Felpina F and Fouqueta E 2008 Adv. Synth. Catal. 350 863

13. Qin Y, Wei W and Luo M 2007 Synlette 152410

14. Felpin F, Fouquet E and Zakrib C 2009 Adv. Synth. Catal. 351649

15. Li X, Yan X, Chang H, Wang L, Zhang Y, Chen W Li Y and Wei W 2012 Org. Biomol. Chem. 10495

16. Siamaki A R, Khder A S, Abdelsayed V El-Shall M S and Gupton B F 2011 J. Catal. 2791

17. Geim A K and Novoselov K S 2007 Nat. Mater. 6183

18. Hass J, de Heer W A and Conrad E H 2008 J. Phys. Condens. Matter 20323

19. Ramanathan T, Abdal A A, Stankovich S, Dikin D A, Herrera-Alonso M, Piner R D, Adamson D H, Schniepp H C, Chen X, Ruoff R S, Nguyen S T, Aksay I A, Prud'homme R K and Brinson L C 2008 Nat. Nanotechnol. 3327

20. Seger B and Kamat P V 2009 J. Phys. Chem. 1137990

21. Deshmukh K M, Qureshi Z S, Bhatte K D, Venkatesan K A, Srinivasan T G, Vasudev Rao P R and Bhanage B M 2011 New J. Chem. 352747

22. Uberman P M, Perez L A, Lacconi G I and Martin S E 2012 J. Mol. Catal. 363245

23. Shendage S, Patil U and Nagarkar J 2013 Tetrahedron Lett. $\mathbf{5 4} 3457$

24. Hummers W S and Offeman R E 1958 J. Am. Chem. Soc. 801339 